\title{
SENSORIAMENTO REMOTO E GEOPROCESSAMENTO APLICADOS AO USO DA TERRA EM MICROBACIAS HIDROGRÁFICAS, BOTUCATU - SP
}

\author{
SÉRGIO CAMPOS ${ }^{1}$, ARMINDO A. ARAÚJO JÚNIOR ${ }^{2}$, ZACARIAS X. BARROS ${ }^{1}$, \\ LINCOLN G. CARDOSO ${ }^{1}$, EDSON L. PIROLI ${ }^{2}$
}

\begin{abstract}
RESUMO: O presente trabalho teve como objetivo identificar e quantificar o uso da terra em dez microbacias ocorrentes na bacia do Rio Capivara, município de Botucatu - SP, a partir da estruturação de um banco de dados utilizando o Sistema de Informações Geográficas (SIG) - IDRISI. Os resultados mostram que as classes de uso da terra, "uso agrícola" e "pastagem", foram as mais significativas, pois ocuparam mais da metade da área das microbacias. O alto índice de uso da terra por pastagens, capoeiras, reflorestamento e matas reflete a predominância de solos arenosos com baixa fertilidade. As imagens obtidas do satélite LANDSAT 5 permitiram o mapeamento do uso da terra de maneira rápida, além de fornecer um excelente banco de dados para futuro planejamento e gerenciamento das atividades agropecuárias regionais. O SIG-IDRISI permitiu identificar, por meio de seus diferentes módulos para georreferenciamento, classificação digital e modelo matemático, as classes de uso da terra com rapidez.
\end{abstract}

PALAVRAS-CHAVE: imagem de satélite, SIG-IDRISI, conservação do solo.

\section{REMOTE SENSING AND GIS APPLIED TO STUDY THE LAND USE IN WATERSHEDS IN BOTUCATU, BRAZIL}

SUMMARY: This study aimed to identify and quantify the land use in ten watersheds in the Capivara river-basin, in the municipality of Botucatu - SP, Brazil. A database was made using the Geographical Information System - IDRISI. The results showed that the classes of agriculture and pasture were the most significant land use, as they occupied more than half of the area of the watersheds. The high index of land use by pasture, brushwood, reforestation and forests, reflected the predominance of sandy soils with low fertility. The images of the satellite LANDSAT-5 allowed the mapping of the land use in a fast and reliable way. In addition they supplied an excellent database for future planning and management of the regional agricultural activities. GIS - IDRISI allowed the identification, digital classification and mathematical modeling of several areas of land use.

KEYWORDS: satellite image, GIS-IDRISI, soil conservation.

\footnotetext{
${ }^{1}$ Prof. Adjunto, Departamento de Engenharia Rural, Faculdade de Ciências Agronômicas - UNESP, Botucatu - SP, Fone: (0XX14) 6802.7165, e-mail: seca@fca.unesp.br

${ }^{2}$ Doutorando do Programa de Pós-Graduação em Agronomia, Departamento de Engenharia Rural, Faculdade de Ciências Agronômicas, - UNESP, Botucatu - SP . 


\section{INTRODUÇÃO}

Com o passar dos anos, a região de Botucatu tem sofrido explorações predatórias e má utilização do solo, principalmente devido aos métodos inadequados e à falta de planejamento do uso da terra, acarretando assoreamento dos rios e reservatórios (CAMPOS, 1997).

$\mathrm{O}$ sensoriamento remoto e o geoprocessamento constituem-se em técnicas fundamentais para a manutenção de registros do uso da terra ao longo do tempo. As imagens de satélite, em forma digital ou papel, são muito importantes e úteis, pois permitem avaliar as mudanças ocorridas na paisagem de uma região e num dado período, registrando a cobertura vegetal em cada momento.

A deterioração dos recursos naturais, principalmente solo e água, vem crescendo intensamente, atingindo níveis críticos, observada pelo assoreamento e poluição dos cursos e espelhos d'água. Em função disso, têm-se observado grande prejuízo à saúde dos seres vivos, destruição de estradas, de pontes e bueiros, riscos na geração de energia, escassez de água para irrigação e abastecimento, redução da produtividade agrícola, diminuição da renda líquida e, conseqüentemente, empobrecimento do meio rural com reflexos danosos para a economia nacional (BRASIL, 1987).

A análise de características, como cobertura vegetal, topografia, drenagem e tipo de solo, permite chegar ao uso racional e adequado de um determinado espaço geográfico. Dessa maneira, determinam-se áreas de preservação de mananciais, reservas florestais, áreas agrícolas, distritos industriais e áreas de expansão urbana, para que o uso do solo obedeça às características naturais da bacia, e o planejamento considere o desenvolvimento sustentado (TUCCI, 1993).

Segundo VALENTE \& CASTRO (1983), uma das dificuldades para o planejamento é a conciliação entre os programas conservacionistas e a exploração econômica. Muitas vezes, os proprietários dos minifúndios que ocupam a bacia hidrográfica, salvo raras exceções, são pouco sensíveis aos aspectos da conservação do solo e da água.

A deterioração e a poluição dos recursos naturais podem ser modificadas com a implantação de um programa racional de utilização e manejo desses recursos, com a participação total e direta das comunidades rurais (ASSAD et al., 1993). Para o alcance dessa meta, deve-se começar com o incremento da produção e da produtividade agrossilvopastoril, diminuição dos riscos de seca e de inundações, redução dos processos erosivos e preservação e/ou recuperação de reservas florestais nativas e de matas ciliares.

Este trabalho teve o objetivo de analisar o uso das terras em dez microbacias ocorrentes na bacia hidrográfica do Rio Capivara, Botucatu - SP, utilizando o Sistema de Informações Geográficas IDRISI, visando a apresentar sugestões de ações corretivas para as áreas deterioradas na região, com vistas ao desenvolvimento sustentado regional.

\section{MATERIAL E MÉTODOS}

A área de estudo compreendeu dez microbacias hidrográficas do Rio Capivara - Município de Botucatu - SP, onde há um grande número de microprodutores. A bacia compreende 21.912,13 ha e está limitada pelas coordenadas geográficas de $48^{\circ} 17^{\prime} 34^{\prime \prime}$ a $48^{\circ} 26^{\prime} 28^{\prime \prime}$ de longitude W Gr. e $22^{\circ} 43$ ‘3" a 22॰57`39" de latitude S.

A primeira etapa do trabalho consistiu na construção de uma base cartográfica da área de estudo, utilizando o Sistema de Informações Geográficas - IDRISI. Esse aplicativo de geoprocessamento, por meio de seus módulos, permite a realização de múltiplas tarefas necessárias para obter uma análise visual e posterior tomada de decisão para planejamentos agropecuários. Na coleta e confirmação das coordenadas dos pontos de controle a campo, foi utilizado um GPS. 
A identificação e o mapeamento do uso da terra e a sua quantificação por meio da classificação supervisionada foram realizados após a elaboração de uma composição falsa-cor, a partir de dados coletados pelo sensor "Thematic Mapper" do Landsat-5, nas bandas 3; 4 e 5, com as cores azul, verde e vermelha, respectivamente. A passagem foi a de 18-9-1999 e corresponde à órbita 220, ponto 76, quadrante A. Nessa composição, os corpos d'água mostram-se em tons azulados, as florestas e outras formas de vegetação em tons esverdeados e os solos expostos em tons avermelhados.

Em seguida, foi feito o georreferenciamento da imagem, utilizando o módulo "Reformat/ Resample" do SIG-IDRISI, sendo os pontos de controle para o georreferenciamento obtidos nas cartas topográficas de Botucatu - SP, e de Pratânia, em escala 1:50.000 e confirmados no campo com o GPS de Navegação Garmin XL 45. Após o georreferenciamento, foi feito o recorte da área de estudo, sendo extraídas posteriormente as áreas das dez microbacias hidrográficas experimentais do Rio Capivara e demarcadas as áreas de treinamento sobre a imagem com o cursor e o "mouse" em vários locais, procurando-se abranger todas as variações de cada ocupação do solo em cada microbacia.

Em seguida, foram criadas as assinaturas pelo módulo "Makesig" e depois a classificação supervisionada pelo método de Máxima Verossimilhança, utilizando-se do módulo "Maxlike".

$\mathrm{Na}$ classificação supervisionada, as ocupações do solo foram identificadas e diferenciadas em seis classes de usos das terras representadas por mata, uso agrícola, reflorestamento, pastagens, solo exposto e capoeira pelos seus padrões de resposta espectral. As áreas de treinamento foram delimitadas por polígonos desenhados sobre cada uso da terra na imagem. Em seguida, foram indicados os nomes de cada classe de uso da terra, associados aos seus respectivos identificadores na caixa-texto, criandose um arquivo de assinaturas para as categorias. A imagem foi classificada com base nesses dados, e as amostras de uso da terra duvidosas foram confirmadas a campo, com o uso do GPS de navegação Garmin XL 45.

As áreas dos usos das terras ocorrentes em cada microbacia experimental do Rio Capivara foram determinadas utilizando o comando "Área" do menu "Data Base Query", pertencente ao módulo "Analysis". Posteriormente, foram também calculadas as porcentagens de cada classe.

Para a identificação digital dos alvos em suas cores reais, foram utilizadas as chaves de interpretação para imagens, propostas por ROCHA (1986).

\section{RESULTADOS E DISCUSSÃO}

A cobertura vegetal (Tabela 1) mais significativa foi o uso agrícola, ocupando quase 1/3 da área total das microbacias. Essas áreas, de maneira geral, estão cobertas com cana-de-açúcar, café, cítrus e outras. A área de cítrus vem aumentando na região de Botucatu, favorecendo a ocorrência de um novo pólo citrícola no Estado de São Paulo.

Os usos da terra das dez microbacias estudadas mostram que grande parte da superfície dessas estão ocupadas por cobertura florestal (mata, capoeira e reflorestamento). Percebe-se que, em média, mais de 30\% das superfícies das microbacias estão ocupadas com vegetação arbórea do tipo mata e capoeira (Tabela 1). Esse é um parâmetro muito importante, pois, de acordo com ROCHA (1991), as matas são fundamentais no controle de erosão e de enchentes, uma vez que, estando situadas em locais adequados, são fundamentais na recarga do lençol freático.

As pastagens, mesmo sendo mal conduzidas, formam a segunda maior área de cobertura vegetal, pois a pecuária bovina de leite tem predominância na região. De maneira geral, a pecuária na região é desenvolvida de forma extensiva, com pastagens de baixa produtividade, observando-se que os produtores não costumam efetuar correções de $\mathrm{pH}$ e adubação de manutenção nessa cobertura vegetal para melhorar a qualidade desse alimento animal. Como a conservação do solo é uma prática agronômica mal utilizada pelos pecuaristas, os solos que, por natureza, são pobres, acabam sofrendo 
com a ação das intempéries, acarretando assoreamento do Rio Capivara, Botucatu - SP, diminuindo, conseqüentemente, a capacidade de suporte da pastagem para o gado e contribuindo para a queda da produção leiteira.

TABELA 1. Uso da terra das dez microbacias hidrográficas ocorrentes na bacia do Rio Capivara, Botucatu - SP, obtido pelo Sistema de Informações Geográficas - IDRISI, em 1999.

\begin{tabular}{|c|c|c|c|c|c|c|c|c|c|c|c|c|c|}
\hline \multirow{3}{*}{ Microbacia } & \multicolumn{13}{|c|}{ Uso da Terra } \\
\hline & \multicolumn{2}{|c|}{ Uso Agrícola } & \multicolumn{2}{|c|}{ Reflorestamento } & \multicolumn{2}{|c|}{ Pastagens } & \multicolumn{2}{|c|}{ Solo Exposto } & \multicolumn{2}{|c|}{ Capoeira } & \multicolumn{2}{|c|}{ Mata } & \multirow{2}{*}{$\begin{array}{c}\text { Total } \\
\text { ha }\end{array}$} \\
\hline & ha & $\%$ & ha & $\%$ & ha & $\%$ & ha & $\%$ & ha & $\%$ & ha & $\%$ & \\
\hline 1 & $1.075,56$ & 6,69 & 775,88 & 4,83 & $1.073,94$ & 6,68 & 48,44 & 0,30 & 863,06 & 5,37 & 170,31 & 1,06 & $4.007,19$ \\
\hline 2 & 131,63 & 0,82 & 165,88 & 1,03 & 120,06 & 0,74 & 0,00 & 0,00 & 151,50 & 0,94 & 38,94 & 0,24 & 608,01 \\
\hline 3 & 74,69 & 0,47 & 635,63 & 3,95 & 6,13 & 0,04 & 0,00 & 0,00 & 83,50 & 0,52 & 36,06 & 0,22 & 836,01 \\
\hline 4 & 405,19 & 2,52 & 178,06 & 1,11 & 284,94 & 1,77 & 19,38 & 0,12 & 138,31 & 0,86 & 81,19 & 0,51 & $1.107,07$ \\
\hline 5 & $1.217,85$ & 7,58 & 94,56 & 0,59 & 768,56 & 4,78 & 30,50 & 0,19 & 615,19 & 3,83 & 408,56 & 2,54 & $3.135,22$ \\
\hline 6 & 127,13 & 0,79 & 19,75 & 0,12 & 517,38 & 3,22 & 0,00 & 0,00 & 117,31 & 0,73 & 174,50 & 1,09 & 956,07 \\
\hline 7 & 482,50 & 3,00 & 13,25 & 0,08 & 174,50 & 1,09 & 3,88 & 0,02 & 88,69 & 0,55 & 203,69 & 1,27 & 966,51 \\
\hline 8 & 349,31 & 2,17 & 18,25 & 0,11 & 121,81 & 0,76 & 2,00 & 0,01 & 95,13 & 0,59 & 166,00 & 1,03 & 752,50 \\
\hline 9 & 953,75 & 5,93 & 23,94 & 0,15 & 509,50 & 3,17 & 2,63 & 0,02 & 270,00 & 1,68 & 291,31 & 1,81 & $2.051,13$ \\
\hline 10 & 216,19 & 1,34 & 185,56 & 1,15 & 283,00 & 1,76 & 0,00 & 0,00 & 826,31 & 5,14 & 144,94 & 0,90 & $1.656,00$ \\
\hline Total & $5.033,80$ & 30,31 & $2.110,76$ & 13,13 & $3.859,82$ & 24,01 & 106,83 & 0,06 & $3.249,00$ & 20,21 & $1.715,50$ & 10,67 & $16.075,71$ \\
\hline
\end{tabular}

O reflorestamento foi outra atividade muito importante ocorrente nas microbacias, pois na região existem muitas companhias reflorestadoras. Essa cobertura vegetal representa 13,13\% da área total das microbacias, variando de 0,08 a 4,83\%. O reflorestamento, além de ser eficiente na proteção da rede de drenagem em regiões com processos erosivos (CARDOSO, 1988), tem grande influência no mecanismo hidrológico, retardando e desviando o escoamento superficial e, conseqüentemente, a erosão (VIEIRA, 1978), além de atender às necessidades econômicas na substituição das derrubadas das matas e cuja regeneração é lenta.

As matas, capoeiras e pastagens representam mais de $40 \%$ da área abrangida pelas microbacias, refletindo assim a predominância de solos de baixa fertilidade, conforme BARROS et al. (1990) e CAMPOS (1993).

\section{CONCLUSÕES}

As imagens do Satélite LANDSAT 5 - TM permitiram o mapeamento do uso da terra da bacia de maneira rápida, além de fornecer um banco de dados para a classificação supervisionada e para futuros planejamentos nessa área.

O SIG-IDRISI permitiu constatar, por meio de seus diferentes módulos para georreferenciamento, classificação digital do uso da terra e modelo matemático, as áreas de uso da terra com rapidez.

As microbacias vêm sendo preservadas, pois as coberturas florestais (matas, capoeiras e reflorestamento) representam mais de $40 \%$ da área total das microbacias, enquanto o mínimo exigido por lei é $20 \%$.

O alto índice de uso da terra por povoamentos com reflorestamento, pastagens, capoeiras e matas refletem a predominância de solos arenosos com baixa fertilidade.

As classes de uso da terra, uso agrícola e pastagem predominaram em mais da metade das microbacias, mostrando a importância da agropecuária regional. 


\section{REFERÊNCIAS BIBLIOGRÁFICAS}

ASSAD, E.D.; SANO, E.E.; MEIRELLES, M.L.; MOREIRA, L. Estruturação de dados geoambientais no contexto de microbacia hidrográfica. In: ASSAD, E.D.; SANO, E.E. (Ed.) Sistema de Informações Geográficas: aplicações na agricultura. Planaltina: EMBRAPA-CPAC, 1993. cap. 4, p.88-108.

BARROS, Z.X. de; PIEDADE, G.C.R.; CURI, P.R. Variáveis de ocupação do solo e análise multivariada. Revista de Geografia, São Paulo, n.8/9, p.11-19, 1990.

BRASIL. Ministério da Agricultura. Comissão Nacional de Coordenação do Programa Nacional de Microbacias Hidrográficas, 1987. p.60.

CAMPOS, S. Fotointerpretação da ocupação do solo e suas influências sobre a rede de drenagem da bacia do rio Capivara - Botucatu (SP), no período de 1962 a 1977. 1993. 164 f. Tese (Doutorado em Energia na Agricultura) - Faculdade de Ciências Agronômicas, Universidade Estadual Paulista, Botucatu, 1993.

CAMPOS, S. Diagnóstico físico conservacionista da bacia do Rio Lavapés - Botucatu (SP). 1997. 140 f. Tese (Livre-Docência) - Faculdade de Ciências Agronômicas, Universidade Estadual Paulista, Botucatu, 1997.

CARDOSO, L.G. Comportamento das redes de drenagem em solos com cana-de-açúcar e com eucalipto. 1988. $139 \mathrm{f}$. Tese (Doutorado em Energia na Agricultura) - Faculdade de Ciências Agronômicas, Universidade Estadual Paulista, Botucatu, 1988.

ROCHA, J.S.M. da. Manual de interpretação de aerofotogramas. Santa Maria: Universidade Federal de Santa Maria, 1986. 58 p.

ROCHA, J.S.M. da. Manual de manejo integrado de bacias hidrográficas. Santa Maria: Universidade Federal de Santa Maria, 1991.181p.

TUCCI, C.E.M. Hidrologia: ciência e aplicação. Porto Alegre: Editora da Universidade/ABRH, 1993. cap.1, p.25-33; cap.22, p.849-75.

VALENTE, O.F.; CASTRO, P.S. A bacia hidrográfica e a produção de água. Informe Agropecuário, Belo Horizonte, v.9, p.54-6, 1983.

VIEIRA, N.M. Estudo geomorfológico das voçorocas de Franca - SP. 1978. 255 f. Tese (Doutorado em História) - Instituto de História e Serviço Social, Universidade Estadual Paulista, Franca, 1978. 